\title{
FILOSOFÍA Y POLÍTICA EN LOS AÑOS 20 EN ARGENTINA. LECTURAS DEL IDEALISMO ITALIANO
}

\author{
María Carla Galfione \\ Universidad Nacional de Córdoba, Argentina \\ Consejo Nacional de Investigaciones Científicas y Técnicas
}

http://dx.doi.org/10.5209/rev NOMA.2016.v47.n1.52396

\begin{abstract}
Resumen: El tránsito de una matriz positivista a una idealista en la filosofía académica argentina puede ser leído como producto de una contaminación paulatina y problemática que estuvo fuertemente atravesada por consideraciones que excedieron los aspectos teóricos. Partiendo de la voluntad de explorar ese tránsito, el artículo se detiene en uno de los episodios de esa contaminación: las lecturas que se hicieron en la Revista de Filosofía de la filosofía de Croce y Gentile. Observando allí cierta posibilidad de diálogo entre los presupuestos positivistas desde los que se posicionaba la Revista y el idealismo, se analiza cómo ese diálogo y sus límites estaban condicionados por una consideración política. Si el idealismo era condenado, ello se debía centralmente la actuación de sus teóricos durante los primeros años del gobierno de Mussolini. Si, por su parte, algo había para rescatar de esa filosofía, era el hecho de que aportaba elementos importantes para pensar el cambio revolucionario.
\end{abstract}

Palabras claves: Filosofía, Cientificismo Idealismo italiano, Fascismo, Revolución

\section{Philosophy and Politics in the 20th in Argentina. Readings of Italian Idealism.}

Abstract: The transition from a positivist matrix to an idealistic one in Argentinean academic philosophy can be read as a result of a gradual and problematic pollution. It was, also, heavily traversed by considerations that exceeded the theoretical aspects. Based on the willingness to explore this transit, the article pays attention to one of the episodes of this contamination: how the Revista de Filosofía reads Croce and Gentile's philosophy. Observing there some possibility of dialogue between positivist assumptions, with which the journal takes a position, and the idealism the article analyze how this dialogue and its limits were given from a political consideration. If the idealism was condemned, it is centrally owed to its performance during the first years of the government of Mussolini. If, meanwhile, it was some to rescue of that philosophy, it was that it contributed to think the revolutionary change.

Keywords: Philosophy, Scientism, Italian idealism, Fascism, Revolution

El convulsionado inicio del siglo $X X$ en Argentina es, entre otras cosas, un momento en que se comienzan a definir algunas de las corrientes filosóficas que habrían de dominar la escena académica durante la primera mitad de siglo. Esas definiciones y los debates que suscitaron están entramados en un marco más general que nos remite a las transformaciones que se operaban en otros registros de la vida política y cultural del país y del mundo, y, junto con ello, suponen un posicionamiento frente a algunas de las grandes corrientes de pensamiento filosófico, centralmente europeo, en relación con las cuales buscan el establecimiento de sus principios más básicos y persiguen su reconocimiento. Dicho de otro modo, los debates sobre la filosofía pueden leerse inscriptos en una doble cartografía, una de mayor alcance desde la que se avizoran los grandes 
cambios históricos que le son contemporáneos y una más específica relativa al campo mismo de la filosofía.

Sobre ese doble registro, en lo que sigue nos interesa atender al modo en que las posiciones filosóficas locales se ubicaban en el universo más general de la filosofía idealista que en Europa hacía frente a los resabios del positivismo y del materialismo. En términos generales, lo que aquí se conoció como "positivismo" y que dominaba el campo del saber científico desde fines del siglo XIX fue presentado muchas veces como refractario a estas novedades. Sin embargo, así como ese positivismo no fue algo uniforme, el rechazo que éste ejercía sobre aquellas corrientes tampoco es unánime ni encuentra una sola justificación, y mucho menos a medida que avanza el siglo XX. En lo que sigue nos proponemos una lectura que indaga en esa clave. Bajo la pregunta general acerca el tránsito que llevaba del positivismo al predominio de otras expresiones en el campo filosófico argentino podemos ver los modos en que se producía cierta contaminación, advirtiendo al mismo tiempo que la mezcla nos remite necesariamente a las condiciones externas que mencionamos arriba.

En otros trabajos nos hemos ocupado de las definiciones de filosofía que auspiciaba la Revista de Filosofía a través principalmente de su creador, José Ingenieros, pero también de algunos de sus colaboradores más cercanos. Del mismo modo, sumando nuestro trabajo a otras indagaciones recientes, hemos caracterizado la Revista de Filosofía y hemos avanzado sobre la identificación de sus autores. (Autor; Fernández, 2012; Rossi, 1999) Aquí nos interesa, en cambio, detenernos en la mirada que ofrece la Revista de algunas de las posiciones más distantes del positivismo, confiando en que una lectura de este tipo nos permita comprender el desplazamiento o tránsito entre las diversas posiciones filosóficas en éste que consideramos un momento fundante de la filosofía académica en el país.

\section{1. ¿Tontos o cínicos?}

En 1923 se publican en la Revista de Filosofía algunos artículos que giran en torno a las figuras de Croce y Gentile, a la caracterización de su posición filosófica y al análisis de sus intervenciones en la política italiana. El primero de esos artículos fue publicado en el número de marzo y su autor es José Ingenieros, aunque bajo el nombre de Julio Barreda Lynch, su pseudónimo más usual. ${ }^{1}$ Le sigue un texto de Emilio Zuccarini, de mayo, y finalmente, en septiembre, aparece otro artículo de autoría de Ingenieros, en que responde al de Zuccarini. Hay, sin embargo, otras

\footnotetext{
${ }^{1}$ Aprovechamos esta instancia inicial para advertir que la centralidad que damos en este trabajo a la figura de José Ingenieros se deriva principalmente de la posición que este autor ocupa en la Revista, de la cual es el principal mentor desde 1915, año en que la funda, y de la que será su director hasta 1925, en que muere, aunque la Revista seguirá publicándose hasta 1929. Del mismo modo, hacemos notar que tomamos la publicación como un conjunto medianamente homogéneo, suponiendo la expresión de ideas comunes a sus autores, a excepción de algún caso que se indicará cuando sea necesario. Esa comunidad de posiciones, sin que sea suficiente para referirnos a un colectivo intelectual, remarca aún más la centralidad de su director que era quien imprimía una línea editorial definida.
} 
intervenciones, en ese y otros años, que aportan algunos elementos a la temática y que serán considerados también. En las tres contribuciones que contamos como centrales, el tema principal se bifurca en dos líneas: por un lado, la caracterización del idealismo de ambos autores, Croce y Gentile, como posición filosófica más o menos diferenciada y, por el otro, la consideración de la actuación de estos filósofos en el marco de la compleja vida política de Italia en esos años. Ambos temas, de ahí nuestro interés por esos artículos, están completamente tramados y ello se observa en los textos.

El artículo de marzo se titula "Croce y Gentile, fariseos del idealismo" y su objetivo, según lo afirma el autor y a pesar del título, gira en torno al estudio de la formación del idealismo en Italia a través de los filósofos italianos. Temática que, aclaremos, no constituye en absoluto una cuestión menor por tratarse de un país que aportaba singulares figuras a la elaboración teórica del vínculo entre marxismo y positivismo y que, al mismo tiempo, contribuía con esos nombres a la renovación del marxismo que vendría unos años después. Para lograr su objetivo, Ingenieros se detiene medianamente en ambos autores, comenzando con Croce y analizando el tránsito de su pensamiento político desde una marcada cercanía al socialismo hacia posiciones bien distantes de éste. Según lo relata el artículo, si bien en sus primeras intervenciones se caracterizó por la proximidad con los grandes teóricos del marxismo segundointernacionalista, formado en el ambiente napolitano muy próximo a Bovio, a Colajanni y, especialmente, a Labriola, Croce se fue apartando paulatinamente de la militancia socialista hasta distanciarse definitivamente, y no en los mejores términos, en 1900 con su libro Materialismo storico ed economía marxista. En 1911, dice Ingenieros, Croce proclamaría finalmente la muerte de ese socialismo. $^{2}$

La radical distancia de Croce del socialismo es descripta en íntima sintonía con su acercamiento o su interés por la filosofía. De ahí que se marque un tránsito conjunto en el cambio de intereses, de lo literario a lo filosófico, y en la transformación política, de la izquierda a la derecha. Pero lo que realmente parece encontrar allí nuestro autor, más que, simplemente, un cambio disciplinar, es una transformación operada dentro mismo de la concepción filosófica que se sostenía. Sugiere Ingenieros que, si bien Hegel había sido un filósofo preferido por las izquierdas a mediados del siglo XIX, ello no continuaba siendo así hacia finales de ese siglo, en que, en cambio, se polarizaban las posiciones entre las escuelas positivistas, cercanas a las izquierdas políticas, y las espiritualistas o idealistas, próximas a las derechas reaccionarias. (Barreda Lynch, 1923a, p. 164) Habría sido el mismo Croce el que, en 1914, mostró esa relación, citando a Labriola, para afirmar que el idealismo filosófico estaba estrechamente relacionado con la

\footnotetext{
${ }^{2}$ Sin duda hay aquí un error en la fecha, el artículo al que se refiere, "La muerte del socialismo", habría sido publicado en Cultura et vita morale, en 1914. Es interesante recordar que ese texto de Croce fue reproducido en 1921 en la Revista del Centro de Estudiantes de Derecho de la Universidad Nacional de Córdoba. Allí Croce denunciaba los errores en que había caído la lectura histórica propuesta por el marxismo, errores que podían notarse a la luz del curso que tomaban los acontecimientos en los últimos años. Allí, el proletariado descripto por Marx era considerado una ilusión que no sólo no resistía los pronósticos de Marx sino que tampoco podía persistir a pesar de los intentos de revitalización que recibiera del sindicalismo. Cfr. Croce, 1921.
} 
reacción de la burguesía. (Barreda Lynch, 1923a, p. 164) Ese idealismo, que a juicio de Ingenieros no será nunca un verdadero idealismo, es visto en la propuesta de Croce como un arma esgrimida frente al positivismo. $Y$ en esto se distingue de Gentile. Pero ya volveremos a este punto.

El idealismo, presentado como herramienta antipositivista, también puede leerse en el contexto de la Italia de ese momento como aparejo útil a los intelectuales que intentaban vincularse con el poder. Y ello deviene el objeto central del artículo de Ingenieros.

Destacando las diferencias en lo que hace al modo de pensar la religiosidad en Croce respecto de la posición de los autores católicos con mucha influencia en Italia, Ingenieros advierte cómo estos últimos encontraban en el filósofo un aliado importante contra el positivismo. Si bien es claro, para nuestro autor, que el Dios católico no es el Dios croceano, que su religión, insuflada de panteísmo, dista mucho de parecerse a la católica, es cierto también que en términos prácticos la argumentación de Croce venía a constituirse en un arma de la que los católicos no disponían aún. Croce, dice Ingenieros, "les era útil y por eso lo admiraban". (Barreda Lynch, 1923a, p. 169) Porque en definitiva compartían los enemigos: el ateísmo, el materialismo y el positivismo.

Luego de 1870 se produciría, según Ingenieros, un recrudecimiento del liberalismo en los países católicos, y en ese marco, habría de surgir, hacia principios de siglo, la neo-escolástica, propensa a buscar aliados en donde estuvieran. Así, muchos de los neo-escolásticos se formaron en la filosofía moderna, sabían de Kant, de Hegel, de Spencer del mismo modo que sabían de los autores del medioevo. En ese contexto, se funda en 1909 la importante Rivista di filosofía neo-scolastica. Siempre muy respetuosa para con los neohegelianos, sus páginas publicarán, entre 1912 y 1914, artículos de Emilio Chiocchetti en los que se hacen explícitas las diferencias con el hegelianismo de Croce. Sin embargo, insiste Ingenieros sin otro objetivo que poner a prueba su propia tesis, a pesar de las críticas y de la contundencia de las mismas, los neoescolásticos no retiran su apoyo al filósofo y ello se cifraría según él, entre otras cosas, en razones más de tipo estratégico: encontraban en Croce un aliado muy valioso en contra del positivismo, sobre todo porque ocupaba el cargo de senador en el reino de Italia.

Pero dijimos que el artículo se ocupaba también de Gentile y ello se debe en parte al análisis de la propia posición del filósofo italiano, pero en parte también al rol que su filosofía ocupó al servir a la crítica de la posición de Croce. Los argumentos de Chiocchetti en contra de Croce se valen de las críticas que el mismo Gentile le hiciera en función de la distinción entre "idealismo absoluto" e "idealismo actual". En la crítica de Gentile y sus discípulos, entre ellos De Ruggero, el problema del idealismo de Croce radicaría en la persistencia del dualismo, en una especie de vuelta atrás respecto del hegelianismo, por mantener la distinción sujeto-objeto. La filosofía, en Croce, requiere de un objeto-mundo que es el origen de las representaciones, requiere de algún tipo de objetividad de lo real. Y eso es algo que excede las posibilidades del idealismo que viene a proclamar Gentile. Sin embargo, lo que toma de esta crítica el polemista católico Chiocchetti es la no resolución del problema de la trascendencia, que se deriva de la persistencia del 
dualismo. Con todo, si las críticas de Gentile van a servir para profundizar los cuestionamientos católicos a Croce, la revista neo-escolástica no le retira completamente su apoyo.

Ahora bien, Chioccetti cuestiona duramente también la posición de Gentile, esa que antes le había servido de base para elaborar la crítica que dirige a Croce. Si entonces, él observaba con Gentile que la persistencia del dualismo era en Croce una salida que, haciendo de la divinidad un elemento inmanente, no daba una respuesta favorable ante la cuestión de la trascendencia, aquí la resolución del dualismo será, en cambio, el golpe bajo asestado contra la fe. El devenir como condición se da la mano con la negación de toda distinción entre naturaleza y espíritu y juntos resultan un atentado concluyente contra la religiosidad católica.

Ingenieros observa en las diatribas de Chiocchetti y los neo-escolásticos argumentos diferentes que se asientan sobre la misma táctica: primero, con Croce se cuestiona al positivismo, luego Gentile sirve para mostrar las debilidades de la filosofía de Croce y, por último, este mismo también recibe su merecido. Dice Ingenieros, "Chioccetti reconoce la absoluta superioridad de Gentile sobre Croce dentro del idealismo, pero eso mismo obliga a la neo-escolástica a combatirlo con mayor vehemencia". (Barreda Lynch, 1923a, p. 185)

A juicio de Ingenieros parece estar claro que la posición de Gentile sacude al catolicismo. La inmanencia de la religiosidad, el nuevo Dios que coincide con la subjetividad, son elementos que conducen a la negación misma de la trascendencia. Sin embargo, y aquí radica el punto nodal de la crítica más fuerte, ambos autores, Croce y Gentile, se esmeran por ocultar eso que piensan. Profesan una filosofía atea pero temen ser tildados de ateos y, en consecuencia, utilizan las mismas palabras que lo católicos, intentando que la diferencia de sentidos no sea descubierta.

"¿Tontos o cínicos?”, se pregunta Ingenieros. La estrategia terminaría por evidenciarse en 1921 cuando, al constituirse en Italia un ministerio con la cooperación del Partido Católico, Croce fuera nombrado Ministro de Instrucción Pública. Sobra remarcar, a juicio de Ingenieros, que las condiciones que presentaba Croce para ese puesto eran indiscutibles, sin embargo, también advierte que se trataba de un espacio de concertación con los católicos. Es aquí donde la pregunta por el cinismo o la falta de luces se hace más precisa: “¿De manera que todavía, aunque combatiéndolos por sus doctrinas, podían los católicos usar a los idealistas contra alguien?". (Barreda Lynch, 1923a, p. 194) Nosotros podemos preguntarnos: contra quién, algo en lo que Ingenieros no avanza.

Finalmente, en 1922, el primer ministro del fascismo italiano confiaría ese ministerio a Gentile y éste, en consonancia con las tareas para las que había sido designado, aprobará por fin la enseñanza religiosa en las escuelas. Ante ello, la aparente desazón: o estamos ante un fariseo del idealismo o Gentile fue convencido por los argumentos de Chioccetti. La respuesta ya estaba escrita en el título mismo del artículo. 
Emilio Zuccarini toma la posta del artículo de Ingenieros y en mayo propone su lectura del asunto. El artículo, titulado "Algo más sobre Croce y Gentile", es sumamente crítico de la posición que adopta Ingenieros, enfatizando fundamentalmente el hecho de que el problema radica en la filosofía idealista misma. No se trataría, a su juicio, de evaluar los pasos errados que en política habrían dado los portavoces de esta renovación filosófica en Italia, sino de reconocer que esa renovación acarrea también ciertos posicionamientos políticos como algo que le es intrínseco. Según la lectura de Zuccarini, Ingenieros defendería el idealismo aunque poniendo de manifiesto la contradicción entre éste y la práctica. $\mathrm{Y}$, recurriendo a un gesto poco usual en la Revista, siempre respetuosa de su director, no reconoce allí sino el "desahogo de un discípulo del idealismo que ha sufrido inesperadamente un desengaño". (Zuccarini, 1923, p. 321)

Por esta razón, sostiene, Ingenieros no ataca de frente la filosofía de Croce y Gentile sino que se vale de su crítico, el padre Chioccetti primero, el mismo Gentile después, cargando a esas posiciones de las críticas que se le hacen desde el catolicismo. Esa crítica encubierta o quizás desganada, producto del desengaño, se articularía, para el autor de este artículo, con su imposibilidad de reconocer el estrecho vínculo, o la "inevitable relación", que existe entre las posiciones filosóficas y las políticas. Y para demostrar la verdad de esto último, Zuccarini recurre a Bakunin, para quien "el idealismo teórico tendría siempre en la práctica un resultado socialmente contradictorio con las apariencias de sus propios principios". (Zuccarini, 1923, p. 321)

Ello se mostraría a todas luces, dice, torciendo en apariencia el eje de sus afirmaciones, al revisar la actuación de Gentile: la filosofía predicada como un fin de la vida se convierte ahora en un medio para conseguir una determinada posición política y social. $Y$ aquí volvemos a estar cerca de lo que planteaba el artículo anterior. En la presentación de Zuccarini, lo más característico del idealismo termina siendo la simulación, o mejor, la disimulación. Pero así como Ingenieros lo veía en relación con la actuación particular de Croce y Gentile en el Ministerio de Instrucción Pública, Zuccanini lo remarca como la característica misma de la filosofía idealista. Algo que diferencia el idealismo del materialismo o del positivismo es precisamente esto, que en aquél la política compromete al filósofo. Si pretendieron haber derrotado al positivismo, el triunfo finalmente quedó opacado por la consideración de la política.

Aquella idea según la cual idealismo y fascismo se dan la mano, más allá de las simulaciones y de la falta de armonía entre teoría y práctica, se desdibuja en el artículo de Zuccarini. Sin embargo, es algo que está desarrollado con cuidado en su primera colaboración en la Revista, en 1915. Allí, en un artículo titulado "Las consecuencias históricas del idealismo y del positivismo" se ocupaba de vincular algunos hitos de la historia de la filosofía con el pretendido poderío de Alemania y con los acontecimientos de la Guerra. La unidad germánica no se asienta sobre otra base filosófica más que la filosofía de Hegel. Se refiere a "el plan deductivo elaborado por Hegel", (Zuccarini, 1915, p. 249) el autor de "silogismo pangermánico". Aquí también se apoya en Bakunin afirmando lo mismo que 
sostendrá años más tarde: el idealismo se transforma en el más brutal materialismo. Niega la realidad, para crear un mundo nuevo a imagen de su idea. Y el arma es Hegel. ${ }^{3}$

Ahora bien, aunque este artículo permita aclarar más la posición de Zuccarini, no logran evidenciarse verdaderas diferencias con lo que plantea Ingenieros. Sin embargo, este último lo aclara en un texto posterior: "La política inmoral de Croce y Gentile". Allí, el autor vuelve a la carga con las mismas críticas que hiciera unos meses antes, denunciando el filibusterismo de Croce. Él, dice, bregando por la libertad de enseñanza, no ha renunciado a sus creencias, no ha abjurado de éstas, las ha acomodado con hipocresía deliberada a sus fines prácticos, contrarios, aclara, a los que se derivaban de su doctrina. Llama la atención aquí que, en vez de distanciarse del idealismo como estrategia de evasión ante las críticas de su coterráneo, Ingenieros opta por otro tipo de respuesta. Algo que en el artículo de Marzo era presentado con cierta ambigüedad aunque no dejaba de decirse, aquí es en cambio acallado a gritos. Si en aquel texto se sugería el vínculo entre idealismo y reacción al afirmar que el tránsito político que podía observarse en Croce desde el socialismo a la derecha corría en sintonía con el cambio filosófico -"su evolución filosófica coincidió con su evolución política, visiblemente; y así como fue deslizándose hacia la derecha política, se deslizó también hacia la derecha filosófica, aunque en la práctica mucho más de lo que se reflejaba en su doctrina" (Barreda Lynch, 1923b, p. 164) -, en éste ese vínculo se matiza bastante. Aquí estamos claramente ante una jugada oportunista para la cual la filosofía aportaba las armas pero sin tener éstas ya inscripta de antemano la direccionalidad en la que debían usarse. Más incluso, parece suponer una tergiversación de la filosofía misma en el hecho de que los filósofos italianos oculten el estrecho vínculo existente entre el idealismo y el ateísmo. En ello se condensa la "hipocresía filosófica de Gentile". (Barreda Lynch, 1923b, p. 166)

En este artículo, más que en el de marzo, la crítica que la neo-escolástica hizo recaer sobre la obra de estos autores le sirve a Ingenieros para mostrar lo cerca que, en cambio, se encuentra el idealismo de la filosofía profesada por él mismo. Así, Luigi di Rosa, otro de los críticos de la filosofía italiana, y sus artículos de la Rivista de Filosofia Neo-escolastica le sirven para mostrar cómo el idealismo, a pesar de afirmar una causa única, primera e infinita, no busca una teorización que dé cabida a la posibilidad de pensar en un dios diferente al hombre. De ese modo, y de manera inversa a como lo sugería Zuccarini, Ingenieros hace suyas las palabras de los críticos neo-escolásticos no para cuestionar a los idealistas sino para realzar su costado más afín, confirmando que lo que logra la formulación de

\footnotetext{
${ }^{3}$ En la lectura que ofrece allí Zuccarini, reconoce un modelo filosófico que define como "deductivo", al que opone uno "inductivo" que se despliega en Francia y habría obtenido en el último siglo su impulso con Comte. Mientras la ciencia alemana se pone al servicio de la guerra, del ideal de la barbarie, multiplicando y perfeccionando los instrumentos de muerte, el saber positivo en Francia se pone al servicio de la revolución. En la polarización de Zuccarini entre esos dos modelos de razonamiento lógico, la forma inductiva se da la mano con la idea misma de la revolución. En cambio, el predominio de la lógica deductiva la hace impensable. La lógica inductiva está a la base de las transformaciones sociales que han sido perseguidas por los socialistas en Francia. En Alemania, en cambio, la deducción conduce a la conservación.
} 
Gentile es perfeccionar, completar, el materialismo ateo y no, en cambio, fortalecer el teísmo espiritualista. Algo que ya había dicho unos meses antes pero que ahora parece ser afirmado con mayor convicción.

En ese juego de doble farsa, en que los católicos simulan no reconocer las implicancias de las posiciones idealistas y éstos se esmeran por disimularlas, el que sale fortalecido, a juicio de Ingenieros, es el materialismo. En contra de la lectura de Zuccarini, anclada el "monumento muerto" del positivismo de Ardigó, nuestro autor ensaya la adopción de una posición renovada que puede reconocer en el "idealismo inmanente" -opuesto al "espiritualismo trascendente" - un punto de reunión con los idealistas. No descuida discutir duramente la posición política adoptada por los idealistas italianos, pero atento de no arrojar con ellos lo que esa filosofía aporta. De este modo, su artículo termina planteando la posibilidad de una superación: "no ocultamos que nuestra confianza en el idealismo filosófico permanece inalterada a pesar de la inconsecuencia práctica de Croce y Gentile. Y nos parece que si esa confianza tuviera que debilitarse por el estudio y la reflexión, no sería para volver atrás y buscar en el viejo positivismo la solución de los problemas metafísicos que exceden las posibilidades de los métodos científicos, sino para superar el idealismo y el positivismo, el espiritualismo y el realismo, en busca de nuevas doctrinas que satisfagan mejor que las precedentes la eterna inquietud humana de encontrar hipótesis legítimas que expliquen los problemas inaccesible de la experiencia". (Barreda Lynch, 1923b, pp. 174-175)

\section{Hacia un materialismo permeable}

Hay en la Revista otras intervenciones que avanzan sobre cuestiones muy cercanas y que pueden ayudarnos a dar sentido a este debate que puede parecer menor. En primer lugar, se destaca la reproducción de algunos artículos de José Carlos Mariátegui, tal como "Biología del fascismo", ${ }^{4}$ incluido en el número de marzo de 1926. Allí, en la cruda descripción de los derroteros ideológicos de Mussolini y de la conformación y crecimiento del fascismo como política consustancial a su líder, Mariátegui se ocupa, no obstante, del rol que jugaron algunos intelectuales, entre los que sobresale el nombre de Gentile. ${ }^{5}$ En su exposición, el peruano entra en sintonía con las afirmaciones de Ingenieros: los intelectuales vuelven a aparecer como fariseos y es esa actitud "oportunística (sic)" la que está a la base del rol diluido o accesorio asignado a los intelectuales en la historia. (Mariátegui, 1926, p. 337)

Pero esta idea se completa con la centralidad que se adjudica al plano espiritual, aunque ya no sea comprendido como expresión de los intelectuales. Aquí

\footnotetext{
${ }^{4}$ El texto aparece en la Revista fechado en 1925. No hemos podido precisar el origen del texto, aunque hay razones para suponer que se trata de una reproducción del mismo texto aparecido o bien en la revista Variedades o bien en Mundial. Hay en la Revista de Filosofía otros artículos de Mariátegui:" La revolución y la inteligencia", incluido en el número de julio de 1926, "Hechos e ideas de la revolución rusa", publicado en noviembre del mismo año y "Crítica marxista", que aparece en el número de septiembre-noviembre de 1928.

${ }^{5}$ Es importante notar la fecha del artículo de Mariátegui, que supone ya el intento de Croce de distanciarse del fascismo, algo que es mencionado en el mismo texto.
} 
Mariátegui se refiere a la religiosidad. Siendo uno de los elementos más caros al éxito del fascismo, su ausencia es sentida como una de las causas de la debilidad de sus oponentes. A su juicio, Gentile y los filósofos idealistas son útiles al fascismo precisamente por su capacidad de construir una idea que, vista como síntesis, se manifiesta como principio capaz de sostener las convicciones del régimen. En cambio, en la vereda opuesta, habiéndose despojado de todo componente religioso, el liberalismo no alcanza a constituirse como opción. El escepticismo que caracteriza su filosofía, su fuerte criticismo lo hace incapaz de sostener una opción política real. Entre ambos hay, no obstante, otra posición: el "misticismo revolucionario de los comunistas", que sí puede hacerle frente al fascismo.

Otro artículo interesante que avanza en la misma línea que el de Mariátegui, es el de Mariano Barrenechea, "Reflexiones sobre la revolución mundial", publicado en 1922. Allí el autor hace frente al materialismo histórico con la misma voluntad de revisar algunos de sus presupuestos más asentados y en esa empresa Croce es una figura muy relevante. El italiano, leído a través de Materialismo histórico y economía marxista, de 1921, le sirve a Barrenechea precisamente para matizar el materialismo propio del materialismo histórico evadiendo el absoluto privilegio de los factores económicos en la determinación de los fenómenos históricos. El marxismo, dice, puede ser algo diferente de una doctrina abstracta y de difícil comprensión, puede ser reconocido, en cambio, como una doctrina capaz de producir hechos, ideas que penetran en la "sensibilidad de las masas" y desde allí crean, transforman, la realidad social.

Sin embargo, parece fundamental leer la presencia de Croce en este texto de la mano de las otras referencias: Sorel y Nietzsche. Lector del filósofo alemán, Barrenechea intenta hacer dialogar su posición con la del materialismo. Al reconocer el modo en que Nietzsche hace depender la justicia y las ideas, de la fuerza o voluntad, descubre cómo la operación del materialismo histórico ha sido la de valerse de la fuerza propia de un proletariado descontento para llevar adelante su lucha y su discurso contra la explotación y su reclamo de transformación del mundo moral. Si la revolución rusa puede aparecer como "aurora de una nueva era" ello no se debe, según Barrenechea, a la doctrina marxista, a la ortodoxia, sino a los hechos mismos que son explicados. No cabe duda, afirma, que la revolución es uno de los momentos más grandes en la historia de la civilización, pase lo que pase con los bolcheviques, ésta sobrevivirá aunque sea en la forma de mito. ${ }^{6}$

Al decirlo de este modo, Barrenechea se apoya en Sorel, en las Reflexiones sobre la violencia (1908) y en Materiales para una teoría del proletariado (1919). Para el caso de Croce, estaría tomando en esa lectura uno de los aspectos más controvertidos de su crítica a la explicación marxista de la historia, que sería también la base de la distancia que establecía el francés. La doctrina, dice en la Revista de Filosofía refiriéndose a la definición marxista de la historia, no afirma

\footnotetext{
${ }^{6}$ Algo muy similar afirmaba Ingenieros en 1918 en la misma revista en su artículo "Ideales viejos e ideales nuevos": ni importa el resultado de la guerra, ni el tiempo en que se hagan las revoluciones, lo que importa es que éstas renuevan los ideales, renuevan la fe que necesita la humanidad.
} 
que la historia es sólo la historia económica. Incluso se arriesga aún más afirmando que "no hay propiamente materialismo en el verdadero marxismo" porque, tal como afirmaba Sorel en Las ilusiones del progreso, el materialismo histórico no excluye de la historia "ni la voluntad humana, ni la coyuntura de causas ocasionales en la determinación de los hechos sociales, no conduce a la fatalidad ciega e involuntaria en el proceso social". (Barrenechea, 1922, p. 223)

Sorel se mantendría aquí, según este autor, bastante cerca de Marx, y parado allí no sólo afirma la intervención de los grupos sociales en la historia sino el hecho de que dicha intervención estaría siempre acompañada por la construcción de un producto espiritual capaz de desplazar la centralidad otorgada a los aspectos materiales.

Es notable la preocupación que se evidencia por darle a la espontaneidad ${ }^{7}$ un lugar importante en la historia, desplazando de esa manera el predominio de la previsión cientificista, y vinculando esa espontaneidad con la práctica revolucionaria, que pretende avanzar sobre el marxismo aunque no en clave revisionista. Y allí Barrenechea no deja de aproximarse una vez más a Sorel para destacar el lugar de la violencia, del dolor y del sufrimiento como elementos propios y necesarios de la transformación histórica. La violencia revolucionaria, una fuerza diferente a la que impone la burguesía haciendo reinar el orden, es valorada como elemento de cambio, y así lo dice el autor en relación con la revolución rusa: los crímenes son inevitables en las revoluciones, "forman la prenda fundamental de las ventajas y de las conquistas que ellas aportan". (Barrenechea, 1922, p. 227)

El guarecerse en esa fuente de la filosofía próxima al vitalismo, ofrece a nuestro autor la posibilidad de elaborar una explicación de la historia que supere la centralidad otorgada al pasado como condición determinante, para ensayar una mirada del pasado como suelo sobre el que sólo se puede avanzar a condición del despliegue de nuevas ideas. Éstas servirían a fin de cuentas como sustento de esa nueva realidad, aunque ello no signifique que no se formulen a partir de las necesidades reales de los hombres y de su comprensión. En síntesis, podría decirse que las ideas están íntimamente atadas a la experiencia vital. (Barrenechea, 1922, p. 233-234)

Como en todos los momentos de crisis, afirma, "la descomposición presente es garantía de una civilización que se levantará sobre fundamentos nuevos (...). Nuestro escepticismo no es más que una prenda anticipada de una nueva fe (...). Este escepticismo no aniquila en nosotros la vida del espíritu ni los sueños del alma". (Barrenechea, 1922, p. 240) Así, la Revolución puede ser leída como renovación no sólo en términos materiales y políticos, sino también de ideales, advirtiendo que esa novedad no nos devuelve, sin embargo, a posiciones idealistas o trascendentalistas. ${ }^{8}$ Transformación del mundo, novedad, revolución:

\footnotetext{
${ }^{7}$ Quizás convenga recordar, con Gregorio De Paola, que en Sorel esa noción de espontaneidad se derivaría del élan vital de Bergson, de una noción de creación incondicionada.

${ }^{8}$ Hablando del sindicalismo, afirma la necesidad de una "sociedad nueva que se eleve sobre la organización de las fuerzas productoras y de la economía (...); significa el reconocimiento del trabajo como única fuente de las demás actividades del hombre, incluyendo la moral, el arte, la
} 
allí se dan la mano las ideas con los hechos, haciendo de éstos algo diferente a reacciones instintivas e ignorantes de las masas proletarias. $Y$ con esto se avizora finalmente la posibilidad de una "civilización nueva".

En este sentido, Barrenechea no parece alejarse mucho de la posición de Ingenieros. Unos años antes, en la misma revista, contra el regreso a las viejas creencias y a las supersticiones, Ingenieros insistía en la necesidad de las ideas, advertía que la creación de éstas debía ir acompañada de una "clara inteligencia del progreso" para evitar que los escombros del pasado sean confundidos con la "construcción de ideales, arquitecturas del porvenir". (Barreda Lynch, 1918, 118) "Frente al viejo mundo moral -decía- es necesario cultivar una fe optimista en la fuerza de los ideales nuevos (...). La humanidad necesita fe, pero una fe puesta en el futuro, que no le sirva de consuelo sino de esperanza". (Barreda Lynch, 1918, p. 133) Y, del mismo modo que Barrenechea, confiaba en que el despliegue de esa nueva fe requería del movimiento mismo de la vida, que sus posibilidades se distinguían allí donde se percibía el movimiento constante de la vida que traía consigo la promesa de las generaciones venideras. (Barreda Lynch, 1918, p. 134 y Barrenechea, 1922, p. 239)

Aunque menos específicos, hay otros artículos en la Revista que también plantean formulaciones en esta misma dirección. Entre ellos se destaca el de Honorio Delgado, intelectual peruano que participa en la publicación de manera bastante frecuente y cuyas intervenciones dejan permanentemente en claro el predominio de una matriz cientificista a la base de sus formulaciones. Considerando centralmente dos de sus artículos, uno de 1918, "La mentalidad místico-romántica y la filosofía científica", y otro de 1924, "La rehumanización de la cultura científica", se observa allí que, si bien es clara la centralidad de ese paradigma cientificista, en sus desarrollos éste convive con un fuerte interés en torno a la necesidad de formular nuevos ideales. Para Delgado, existe una oposición importante entre una "mentalidad místico-romántica" y una "científica", y en ese marco la "filosofía científica" aparece como la herramienta que permitiría escapar al predominio de la primera, que él mismo habría diagnosticado de la sociedad de su tiempo. Sin embargo, y a pesar de su reivindicación permanente de la noción de "filosofía científica", cuya autoría dice deberle al mismo Ingenieros, insiste también en la necesidad de matizar el valor del pensamiento lógico: invalidarlo, dice, "como instrumento universal de conocimiento". Se trataría, a su juicio, de una operación que permitiría dar lugar no sólo a una renovación permanente del saber, sino también, y gracias a ello, que haría que la "superestructura intelectual", que rige el plano de la moral, se alimentara permanentemente de la realidad de donde debe obtener sus verdades. De ese modo, los ideales que conforman esa superestructura devendría libres de prejuicios y dogmatismos. Así, para hacer frente a esa mentalidad místico-romántica, Delgado no recurre directamente a la lógica y a las estructuras científicas, sino que busca matizarlas, advirtiendo la necesidad de otras expresiones con las que éstas deben combinarse. En el

literatura, la pedagogía, el lujo (...), significa el ateísmo que a la inmensa ilusión suprasensible (...) opone al fin triunfalmente su genio, sus disciplinas, su filosofía, mucho más comprensible de las necesidades del hombre". (Barrenechea, 1922, p. 234) 
artículo de 1924 lo plantea en términos contundentes: el misticismo y la metafísica -dos elementos quizás todavía denostados en el artículo de 1918- son invocados como herramientas de superación del yo cartesiano, que se erige como mentalidad dominadora del mundo, y aproximan al hombre a su "vida íntima".

Del mismo modo que se observa en Delgado, otros autores, en principios reacios o reticentes al discurso religioso y a favor de la racionalidad científica, advierten que aquél cumple un rol en la vida de los hombres y en el desarrollo de la historia. $Y$ de ese modo comprenden la necesidad de articular ambos elementos, haciendo de cada uno de ellos un contralor del otro a los fines de evitar cualquier pretensión de absolutizar. ${ }^{9}$

\section{Posibles lecturas}

Cómo hemos visto, la crítica al idealismo filosófico de los '20 articula dos experiencias: la participación de dos de sus más importantes referentes en un gobierno fascista y la inclinación de aquella filosofía a servir de herramienta para la postulación de valores morales que invocaban imágenes del pasado. Ambas experiencias parecían suficientes para proponerse superar algunos de sus rasgos más característicos. No obstante, esto no significaba desconocer sus virtudes y rechazar lo que esta filosofía implica en términos de novedad, sino todo lo contrario. El idealismo, así planteado, pasado por el cedazo de la crítica y resguardado de caer en la afirmación obsecuente de modelos anquilosados y dogmáticos, parece constituirse en la herramienta que la filosofía científica buscaba para asentar los ideales que venía a proponer. De esto, decía Ingenieros, debe surgir algo nuevo, y recordando la lectura de Oscar Terán, podría pensarse que lo nuevo aparecía junto con un horizonte coloreado con ciertas trazas idealistas que se fundían con el fondo cientificista, sin que éste llegara a perder sus rasgos más marcados.

Si tenemos en cuenta ese doble escenario que planteamos en un comienzo, el de las condiciones de la política mundial y el de la filosofía como campo disciplinar en formación, podemos sugerir algunas lecturas de lo que hemos recogido y presentado aquí, y que deben, no obstante, profundizarse. En términos generales pareciera que nos encontramos ante un dilema que se le presenta a un modelo de comprensión filosófico que se asentaba hasta el momento en el marco de las ciencias naturales y que tenía con éstas una relación muy estrecha: por un lado, con Terán puede decirse que para la fecha de la que nos ocupamos, el espiritualismo filosófico le había arrebatado la hegemonía al positivismo. Luego de 1916, con la venida de Ortega y Gasset a la Argentina el positivismo habría comenzado su retirada. (Terán, 1986, p. 89) Se erigía entonces una nueva filosofía que podía, en términos de Korn, "devolvernos nuestra personalidad conciente, libre y dueña del destino" y que para ello reconocía, ya en 1918, en Croce, Cohen y Bergson, a "los obreros de la hora presente". (Korn, 1944, p. 15) En ese marco, las intervenciones de la Revista que repasamos arriba podrían ser

\footnotetext{
${ }^{9}$ En esta línea se destacan, aunque con diferencias, trabajos de Ramón Melgar, de Arturo Alió, de Rodolfo Senet, etc.
} 
leídas como un modo de reconocer esas nuevas condiciones del campo y amoldarse a ellas. Sin embargo, éstas, así planteadas no conducían a los ojos de los autores de la Revista, a un solo lugar. Y de ahí el dilema. Afirmar el valor del idealismo sin descubrir las posibles consecuencias políticas de éste, era no sólo un riesgo político, sino también un riesgo filosófico. Se descuidaría lo más potente de esa filosofía científica, para descansar en el regazo de un modelo tendencialmente conservador. En contra de esa posibilidad, explorarán al máximo las potencialidades de esa "filosofía científica". Y ésta se vuelve el marco general sobre el cual se va a receptar la novedad.

Ahora bien, si las formulaciones que analizamos son permeables a algunas expresiones idealistas ello parece deberse a que se comenzaría a reconocer cierta carencia al interior del esquema de esa filosofía científica. Se trataba de una insuficiencia que tenía que ver ante todo con la imposibilidad de formular afirmaciones sin correlato experiencial directo. De ser estrictos con las condiciones que el modelo mismo imponía, los ideales en éste, aunque se construyeran sobre la base de la experiencia, entendida como vínculo directo con los fenómenos espacio-temporales, no terminaban de ostentar un estatus seguro. Sin embargo, ello no parecía suficiente como para invocar la renuncia a esos ideales, máxime cuando la historia misma, y por tanto la experiencia, mostraban la productividad éstos. En ese contexto, pensar la revolución, incluir su posibilidad en el marco de una determinada filosofía de la historia, los obligaba al menos a preguntarse por las posibilidades de flexibilizar las condiciones del modelo científico y en ese sentido podía haber llegado la hora de admitir que el futuro requería de ideales. Así lo muestra Ingenieros, entre otros, en el segundo texto que revisamos, en su crítica a Zuccarini y en su advertencia de la cercanía de su propia mirada filosófica con el idealismo inmanente que puso como centro al hombre.

Al juzgar al idealismo no necesariamente incoherente con las diversas formulaciones de la filosofía científica, Ingenieros no juzga el modelo abstracto. Éste, así planteado no parece ser el principal objeto de crítica, ${ }^{10}$ y ello quizás podría leerse como un guiño o una condición impuesta a sus nóveles colegas. Lo que se evalúa, y en ello es claro que difiere radicalmente del tratamiento que ensaya Zuccarini, son las consecuencias de este planteo, el modo en que éste sirvió a ciertos sectores al volcarse sobre la experiencia. El idealismo no es negativo por sí mismo, es negativo sólo en la medida en que se pone al servicio del autoritarismo, un sistema político que no sólo es conservador sino incluso reaccionario.

Así planteado, el problema del idealismo no es sólo político, sino que tiene un presupuesto teórico: éste que se liberó de las condiciones que imponía la ciencia y al emanciparse se olvidó también de una de las prerrogativas más valiosas que ese esquema estaba comenzando a ensayar: la ausencia de verdades absolutas, garantizada por el estricto vínculo que propugnaba entre saber y experiencia.

\footnotetext{
${ }^{10}$ No podemos, sin embargo, dejar de notar el esmero que destina Ingenieros a explicar las críticas del padre Chiochetti a la filosofía de Croce, lo mismo que las objeciones de Gentile y, de paso, puede advertirse que en ellas se presenta como objeto central la reflexión en torno a la dialéctica hegeliana y al modo en que aquél se apropiaba de ésta.
} 
Ahora bien, en el otro extremo, y aquí llegamos al otro aspecto que señalamos al referirnos a las condiciones y transformaciones en medio de las cuales se afirma esta posición en torno a la filosofía, se reconocen ciertos cambios ante los cuales se demora todavía la afirmación de una filosofía. Si la revolución podía explicarse como resultado de fuerzas sociales en disputa, la defensa de ese modelo y de la violencia que suponía debía poder hacerse en términos positivos. Había en ello una apuesta por un ideal. Aquí volvían a reunirse el ideal con la experiencia. Esta última había servido de insumo a la hora de definir el ideal, ahora debía prestarse para la evaluación de la productividad de dicho ideal. La revolución rusa no podía reconocerse como producto fatal de la historia, allí había habido ideas que acompañaron ese movimiento, ideas que servirían a los fines de pensar el antiimperialismo y movilizar a las masas para combatirlo. Ideas que, atadas a lo real, intentaban transformarlo en función de otra imagen de lo que podía ser real.

No sólo no son figuras menores las de Croce y Gentile, sino que es claro que se las está leyendo en función de las posibilidades de repensar una vez más la dialéctica hegeliana y con ella hacer reingresar algún plano ideal en un contexto de pregnancia del materialismo. Aunque es difícil pretender aquí, por la fecha y el contexto de producción de estos textos, que nos encontremos ante un reconocimiento seguro de aquello que la ortodoxia marxista obliga a pensar y ante lo que deben posicionarse los intelectuales -algo que será tratado por otros autores, entre los cuales se cuenta el mismo Mariátegui, unos años más tarde-, sí parece factible advertir al menos una fuerte preocupación por reconocer algunas coordenadas que permitirían revisar ciertos presupuestos desplegados por el materialismo. $Y$ en ese sentido, no es difícil afirmar que estamos ante una mirada que parece querer distanciarse o diferenciarse de la aceptación acrítica de la idea de progreso y que reconoce la necesidad de pensar la noción y la realidad de la revolución, con lo que ello implica en términos de revisión de una filosofía de la historia. $^{11}$

Aceptando en cierto sentido el idealismo aparece, no obstante, un aspecto con el que estos autores no transigen: que las ideas circulen por el aire. Porque la filosofía nace de las necesidades presentes y porque una filosofía que no se asienta en la experiencia, que no se evalúa a partir de su vínculo con lo real, es una filosofía que transa fácilmente con el pasado y puede erigirse en dogma. De este modo, una de las posibles explicaciones del hecho de que el idealismo se haya hecho presente junto a estas expresiones, inicialmente materialistas, puede radicar en la necesidad de apuntalar una filosofía que parece necesitar pensar la revolución. Pero afirmar esto con firmeza supondría, desde ya, recorrer otras fuentes.

\footnotetext{
${ }^{11}$ En este sentido, nos distanciamos de la lectura de Omar Acha de la filosofía de la historia supuesta en Ingenieros. Según este autor se observaría aquí "una mirada reformista y amortiguada del progreso". (Acha, 2006, p. 87)
} 


\section{Bibliografía}

Acha, Omar, (2009) Historia crítica de la historiografía argentina, vol. I, Buenos Aires: Prometeo.

Barreda Lynch, Julio, (1923a) Croce y Gentile, fariseos del idealismo, Revista de Filosofía. Ciencia, Cultura, Educación, Buenos Aires, año IX, 1-3, pp. 161-198.

Barreda Lynch, Julio, (1923b) La política inmoral de Croce y Gentile, Revista de Filosofía. Ciencia, Cultura, Educación, Buenos Aires, IX, 4-6. Pp. 161-175.

Ingenieros, José, (1918) Ideales viejos e ideales nuevos, Revista de Filosofía. Ciencia, Cultura, Educación, Buenos Aires, año IV, 4-6, pp. 118-134.

Barrenechea, Mariano, (1922) Reflexiones sobre la revolución mundial, Revista de Filosofía. Ciencia, Cultura, Educación, Buenos Aires, año VIII, 4-6, pp. 220-240

Croce, B., (1921) La muerte del socialismo, Revista del Centro de Estudiantes de Derecho de la UNC, año 2, nº 9, pp. 59-69.

Delgado, H., (1918) La mentalidad místico-romántica y la filosofía científica, Revista de Filosofía. Ciencia, Cultura, Educación, Buenos Aires, año VI, 4-6, pp. 84-89.

Delgado, H., (1924) La rehumanización de la cultura científica, Revista de Filosofía. Ciencia, Cultura, Educación, Buenos Aires, año X, 1-3, pp. 363-393.

De Paola, Gregorio, (1980) Georges Sorel, de la metafísica al mito, Andreucci, Franco et. Al.., Historia del marxismo. El marxismo en la época de la $1{ }^{\circ}$ internacional, Barcelona: Bruguera.

Fernández, Cristina (2012), José Ingenieros y los saberes modernos, Córdoba: Alción.

Korn, Alejandro, (1944) Incipit vita nova, La libertad creadora, Buenos Aires: Losada.

Mariátegui, José Carlos, (1926) Biología del fascismo, Revista de Filosofía. Ciencia, Cultura, Educación, Buenos Aires, año XII, 1-3, pp. 327-347.

Rossi, Luis, (1999) Los proyectos intelectuales de José Ingenieros desde 1915 a 1925: la crisis del positivismo y la filosofía en la Argentina, en: Ingenieros, José y Ponce, Aníbal, Revista de filosofía. Cultura - Ciencia - Educación, Bernal: UNQ.

Terán, Oscar (1986), José Ingenieros: pensar la nación, Buenos Aires: Alianza.

Zuccarini, Emilio, (1915) Las consecuencias históricas del idealismo y del positivismo, Revista de Filosofía. Ciencia, Cultura, Educación, Buenos Aires, año I, 1-3, pp. 242-264.

Zuccarini, Emilio, (1923) Algo más sobre Croce y Gentile, Revista de Filosofía. Ciencia, Cultura, Educación, Buenos Aires, año IX, 1-3, pp. 321-325. 